\title{
A Japanese Patient with Hereditary Myopathy with Early Respiratory Failure Due to the p.P31732L Mutation of Titin
}

\author{
Yasuteru Sano ${ }^{1}$, Satoko Ota ${ }^{1,3}$, Mariko Oishi ${ }^{1}$, Masaya Honda ${ }^{1}$, Masatoshi Omoto ${ }^{1}$, \\ Motoharu Kawai ${ }^{1}$, Mariko Okubo ${ }^{2}$, Ichizo Nishino ${ }^{2}$ and Takashi Kanda ${ }^{1}$
}

\begin{abstract}
:
Hereditary myopathy with early respiratory failure (HMERF) is caused by titin A-band mutations in exon 344 and is considered quite rare. Respiratory insufficiency can be the sole symptom in the disease course. We herein report the first Japanese HMERF patient with a p.P31732 L mutation in titin. The patient manifested respiratory failure and mild weakness of the neck flexor muscle at 69 years old and showed fatty replacement of the bilateral semitendinosus muscles on muscle imaging. Our case indicates that HMERF with a heterozygous p.P31732 L mutation should be included in the differential diagnosis of muscular diseases presenting with early respiratory failure.
\end{abstract}

Key words: Hereditary myopathy with early respiratory failure (HMERF), myofibrillar myopathy, semitendinosus muscle, cytoplasmic body

(Intern Med Advance Publication)

(DOI: 10.2169/internalmedicine.7733-21)

\section{Introduction}

Respiratory muscle involvement in adults with muscular diseases usually occurs during the advanced stages of such disease and is uncommon at the disease onset. However, various adult-onset hereditary myopathies, including hereditary myopathy with early respiratory failure (HMERF), can be associated with respiratory muscle involvement while patients are still ambulatory (1-3).

Mutations in exon 344 encoding the 119th fibronectin-3 (FN3) domain in the A-band region of the titin gene are associated with HMERF (3-5). The reported mutations mainly show an autosomal dominant inheritance pattern, and only the p.P31732 L mutation has been recognized as a semirecessive or semi-dominant variant (5), showing incomplete penetrance (6).

We herein report the clinical features and histopathological and muscle computed tomography (CT) findings of the first Japanese HMERF patient with a heterozygous p.P31732 L mutation.

\section{Case Report}

The proband was a 69-year-old man. None of his family members, including his parents, siblings and children, had signs of muscle disease (Fig. 1). At 67 years old, he started experiencing dyspnea while farming, which necessitated frequent rests. In the same year, he was found to have atrial fibrillation (AF) without cardiomyopathy. He underwent catheter ablation for AF, leading to the termination of the tachycardia and sinus rhythm.

At 68 years old, he began to have daytime drowsiness. At 69 years old, he felt heart palpitations and fatigue and was diagnosed with heart failure with a low cardiac output due to atrial flutter (AFL). High-density oxygen was administered, and his consciousness level gradually decreased. Thereafter, he presented with respiratory failure with hypercapnic coma and required mechanical ventilation and tracheotomy.

After recovering from the heart failure and AFL, he was admitted to our department for a further investigation regarding a possible neurological cause of his restrictive pul-

\footnotetext{
${ }^{1}$ Department of Neurology and Clinical Neuroscience, Yamaguchi University Graduate School of Medicine, Japan., ${ }^{2}$ Department of Neuromuscular Research, National Institute of Neuroscience, Japan and ${ }^{3}$ Department of Neurology, Tokyo Metropolitan Neurological Hospital, Japan Received: April 11, 2021; Accepted: August 25, 2021; Advance Publication by J-STAGE: October 19, 2021 Correspondence to Dr. Takashi Kanda, tkanda@yamaguchi-u.ac.jp
} 


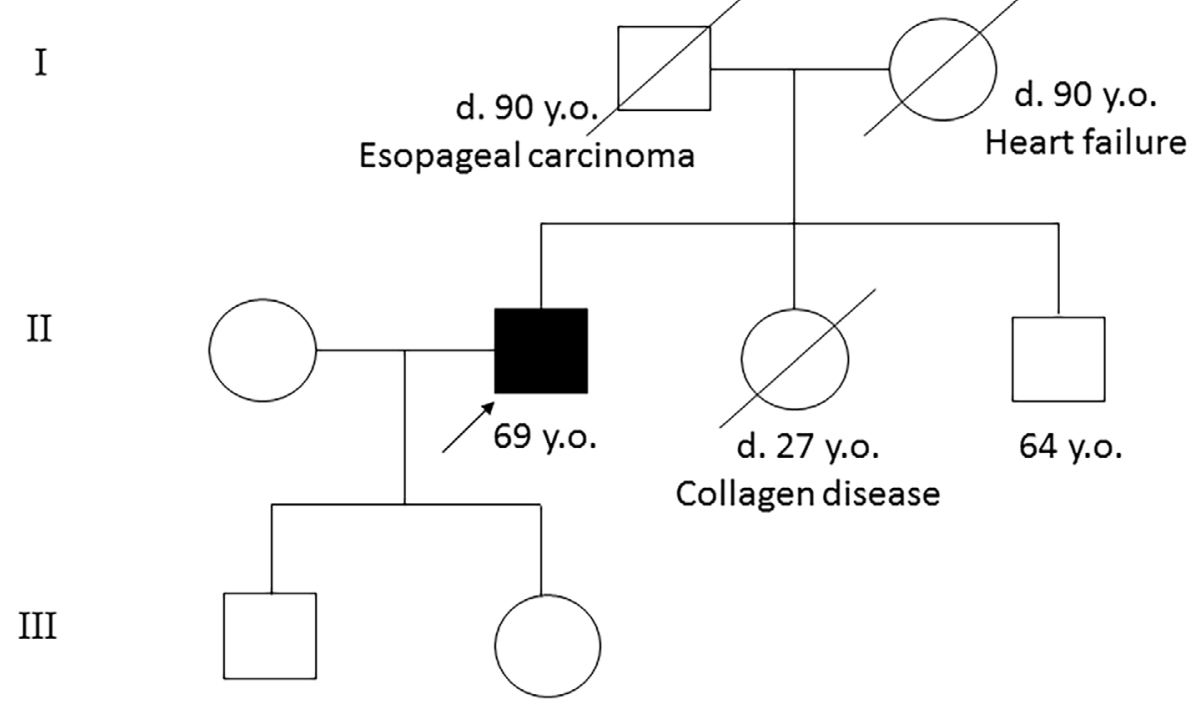

Figure 1. The parents of the proband are not consanguineous. The squares and circles indicate males and females, respectively. The proband is indicated by an arrow and is the only person with this disease in this pedigree. Diagonal lines through symbols represent deceased persons with the cause of death indicated for each person.

A

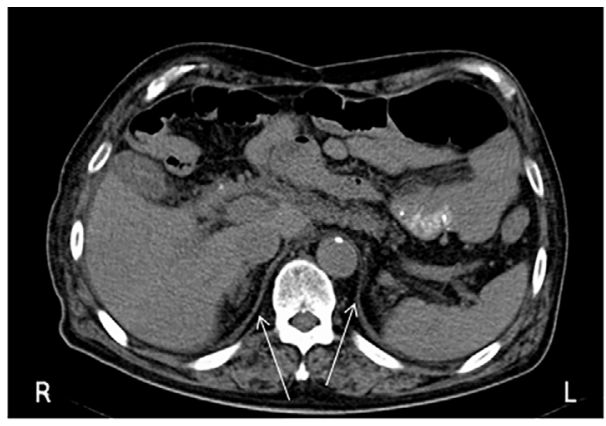

B

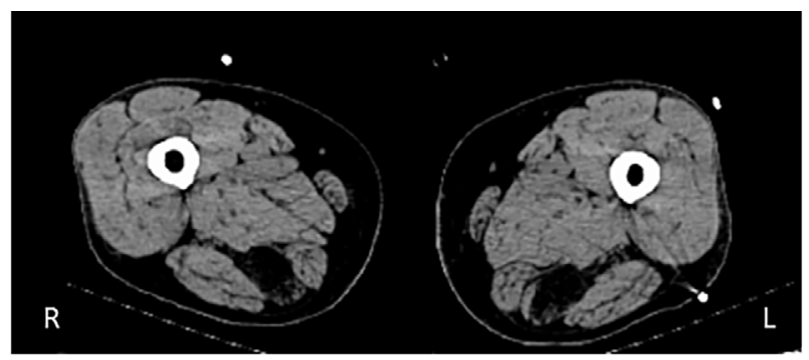

c

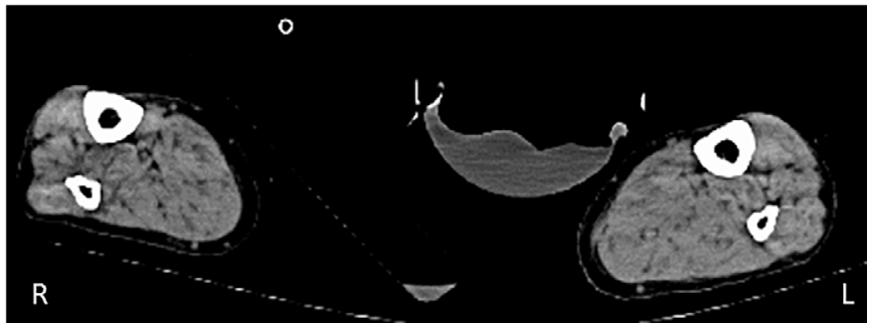

Figure 2. Muscle CT findings of the proband. A: On abdominal CT, atrophy of the diaphragm (arrow) can be seen. B: At the thigh level, fatty degenerative changes in the semitendinosus muscles are noted. C: At the lower leg level, anterior lower muscles, including peroneus longus, are preserved.

monary disease. Although mild weakness of the neck flexor muscles was noted, he had full muscle strength of the upper and lower limbs. His gait was normal before admission, as was his serum creatine kinase level. Chest expansion on respiration was poor, suggesting respiratory muscle involvement, and his forced vital capacity was $61 \%$. An electromyography (EMG) examination of the right semitendinosus muscle showed myopathic abnormalities. Nerve conduction studies were normal. Muscle CT revealed atrophy of the diaphragm (Fig. 2A) and fatty replacement of the bilateral semitendinosus muscles (Fig. 2B). The tibialis posterior muscles were preserved (Fig. 2C). A muscle biopsy performed on the left biceps brachii muscle showed myopathic features, such as increased fiber size variation on hematoxylin-eosin staining (Fig. 3A) and cytoplasmic bodies (CBs) on modified Gomori trichrome staining (Fig. 3B).

He was diagnosed with myofibrillar myopathy (MFM) according to the clinical feature and the CBs on a muscle biopsy. Paired-end sequencing of exons of the genes to screen for MFM, including ACTA1, BAG3, CFL2, CRYAB, DES, DNAJB6, EPG5, FHL1, FLNC, GNE, KBTBD13, KLHL40, LAMP2, LDB3, MATR3, MEGF10, MYH2, MYH7, MYOT, NEB, ORAI1, PABPN1, PLEC, RBCK1, SEPN1, SIL1, STIM 1, TCAP, TIA1, TNNT1, TPM2, TPM3, TRIM32, TTN, VCP and VMA21, was performed using a next-generation Ion PGM $^{\mathrm{TM}}$ sequencer (Thermo Fisher Scientific, Carlsbad, CA, USA) (7). The variants were filtered by allele frequency using public databases, including 1,000 genomes, the Exome 

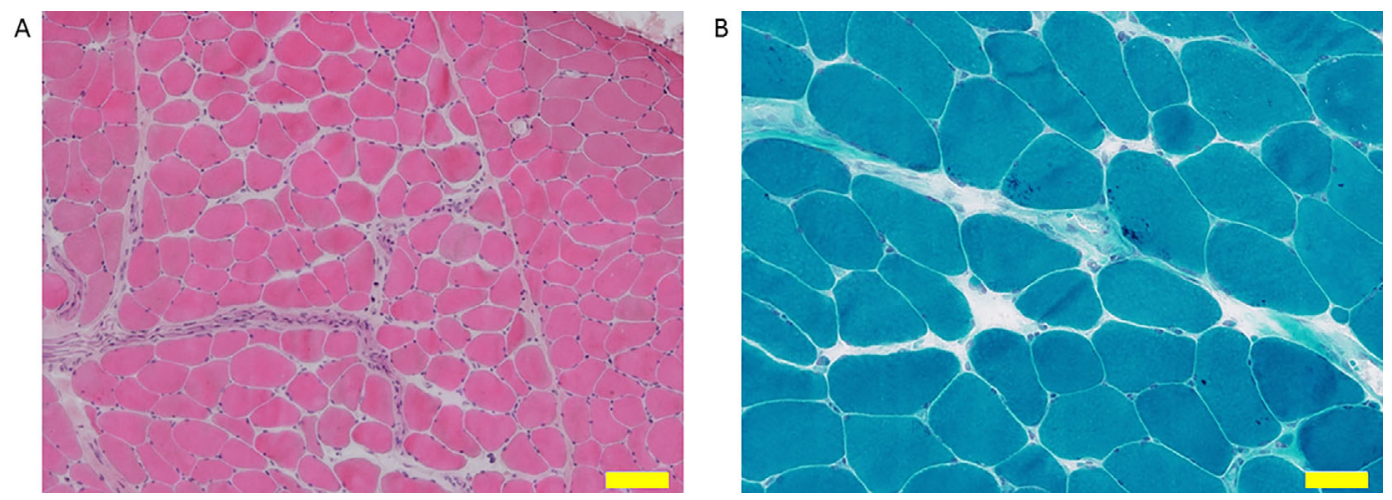

Figure 3. Histopathological features. A: Hematoxylin and Eosin staining shows increased fiber size variation, indicating a myopathic feature (scale bar: 100 microns). B: A modified Gomori trichrome shows cytoplasmic bodies in the subsarcolemmal position (scale bar: 50 microns).

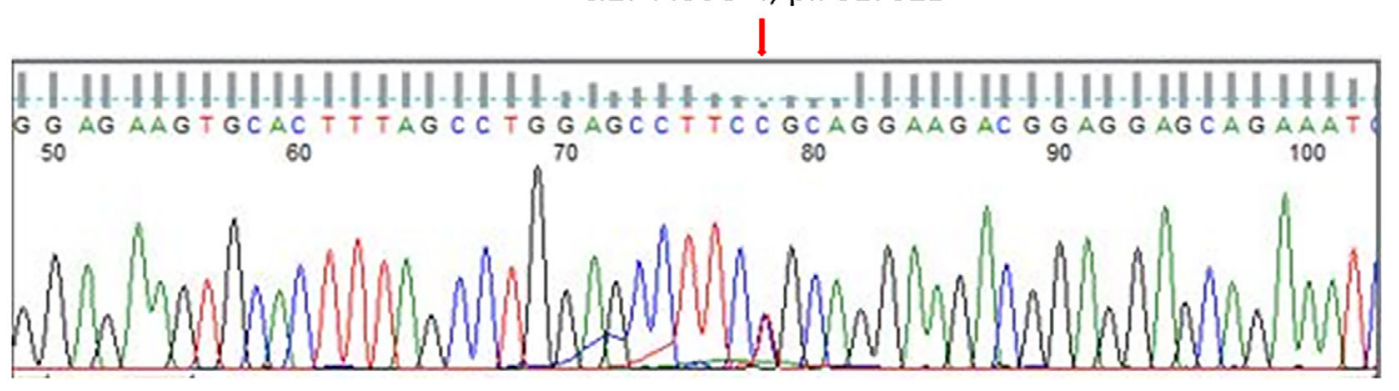

Figure 4. Sanger sequencing confirmed the heterozygous missense mutation [c.274436C $>$, p. P31732L] of the proband.

Aggregation Consortium and ClinVar. To predict the diseasecausing potential for variants, we used Mutation Taster and PolyPhen2, and to evaluate the pathogenicity of the causative variants, we used the American College of Medical Genetics (ACMG) 2015 guideline (8).

Finally, we identified a heterozygous missense variant in TTN on chromosome 2:178546041 in reference to the Genome Reference Consortium Human Genome Build 38 (GRCh38). This variant is listed in gnomAD at an allele frequency of $1.21 \times 10^{-5}$. According to $8.3 \mathrm{KJPN}$, this variant was not identified in 8300 Japanese individuals. In addition, this variant was classified as a 'pathogenic variant' by the ACMG guideline. This variant (g.274436C $>$ T, $($ c.95195C $>$ T; p.P31732 L), NM_001267550.2) was confirmed by Sanger sequencing (Fig. 4). Target re-sequencing did not reveal any variant in the kinase domain of TTN, including p.R34091W, which has been reported to be linked to p.P31732 L in European patients (9). The patient continued invasive nocturnal ventilation support thereafter and was transferred to another hospital for rehabilitation of his respiratory muscles.

\section{Ethics}

All experiments in this study were approved by the Ethics Committees of Yamaguchi University Hospital and the National Center of Neurology and Psychiatry. Written informed consent was obtained from the proband.

\section{Discussion}

Respiratory muscle weakness occurs in a broad variety of neuromuscular diseases during the late stage of the disease. However, this condition can also occur while patients are still ambulatory. Amyotrophic lateral sclerosis (9) and myasthenia gravis (10) are important diseases to consider, but even after these have been excluded, the differential diagnosis of adult-onset hereditary myopathies remains challenging. Naddaf et al. reported that MFM was the second-most common condition after adult-onset Pompe disease among hereditary myopathies as a cause of early respiratory failure (12). Besides HMERF, there have been case reports of patients presenting with respiratory failure in MFM due to mutations in DES (13), CRYAB (14) and BAG3 (15). We should therefore consider MFM as an important differential diagnosis of diseases manifesting as early respiratory insufficiency.

The importance of neuromuscular imaging in recognizing the degree and pattern of muscle involvement is increasing, helping to limit the range of the differential diagnosis and facilitating making the actual diagnosis. The predominant involvement of the semitendinosus on imaging, or even its isolated involvement, is considered specific to a group of MFMs, including HMERF and those caused by mutations in 
Table 1. Japanese Patients with HMERF.

\begin{tabular}{|c|c|c|c|c|c|c|c|c|}
\hline \multirow[t]{2}{*}{ Patient } & \multirow[t]{2}{*}{$\begin{array}{l}\text { Age/ } \\
\text { sex }\end{array}$} & \multirow[t]{2}{*}{$\begin{array}{c}\text { Mutation } \\
\text { (Protein level) }\end{array}$} & \multirow[t]{2}{*}{$\begin{array}{l}\text { Initial manifestation } \\
\text { (age) }\end{array}$} & \multirow[t]{2}{*}{$\begin{array}{l}\text { Respiratory } \\
\text { disturbance } \\
\text { (age) }\end{array}$} & \multicolumn{2}{|c|}{$\begin{array}{l}\text { Selective muscle } \\
\text { involvement on } \\
\text { imaging }\end{array}$} & \multirow[t]{2}{*}{$\begin{array}{l}\text { Foot } \\
\text { drop }\end{array}$} & \multirow[t]{2}{*}{ Reference } \\
\hline & & & & & ST & ACLLs & & \\
\hline A-1 & $49 / \mathrm{M}$ & p.C31712R & Tripping (46) & Yes (48) & NA & NA & + & 19 \\
\hline $\begin{array}{l}\text { A-2 } \\
\text { (Son of A-1) }\end{array}$ & $26 / M$ & p.C31712R & Tripping (20) & Yes $(*)$ & + & + & + & 19 \\
\hline B-1 & $45 / M$ & p.C31712R & Foot drop (31) & Yes (44) & + & + & + & 19 \\
\hline $\begin{array}{l}\text { B-2 } \\
\text { (Younger brother of B-1) }\end{array}$ & $37 / M$ & p.C31712R & Foot drop (27) & Yes (34) & + & + & + & 19 \\
\hline $\mathrm{C}$ & $34 / \mathrm{F}$ & p.C31712R & Fatigability (26) & Yes (26) & + & + & + & 19 \\
\hline $\mathrm{D}$ & $38 / \mathrm{M}$ & p.C31712R & $\begin{array}{l}\text { Difficulty in lifting } \\
\text { theigh }(20)\end{array}$ & Yes (26) & + & - & + & 19 \\
\hline $\mathrm{E}$ & $40 / \mathrm{M}$ & p.C31712R & $\begin{array}{c}\text { Fatigability, respiratory } \\
\text { failure }(31)\end{array}$ & Yes (31) & + & + & + & 19 \\
\hline $\mathrm{F}$ & $52 / \mathrm{M}$ & p.C31712R & Foot drop (47) & Yes (50) & + & + & + & 19 \\
\hline G-1 & $67 / \mathrm{M}$ & p.C31712R & Tripping (57) & Yes $(*)$ & + & + & + & 19,24 \\
\hline $\begin{array}{l}\text { G-2 } \\
\text { (Son of G-1) }\end{array}$ & $38 / \mathrm{M}$ & p.C31712R & Tripping (20) & Yes (29) & + & + & + & 19,24 \\
\hline $\begin{array}{l}\text { G-3 } \\
\text { (Daughter of G-1) }\end{array}$ & $36 / F$ & p.C31712R & Gait disturbance (31) & Yes (34) & + & + & + & 24 \\
\hline $\mathrm{H}$ & $68 / F$ & p.C31712R & $\begin{array}{l}\text { Difficulty in standing } \\
\text { on right toe (68) }\end{array}$ & Yes (68) & + & + & - & 19 \\
\hline I & $43 / \mathrm{M}$ & p.C31712R & Fatigability (39) & Yes (39) & + & + & - & 19 \\
\hline $\mathrm{J}$ & $42 / F$ & p.C31712Y & $\begin{array}{l}\text { Difficulty in lifting } \\
\text { theigh (36) }\end{array}$ & Yes $(*)$ & + & + & - & 19 \\
\hline K & $38 / \mathrm{M}$ & p.G31791D & Gait disturbance (31) & Yes $(*)$ & + & + & + & 19 \\
\hline $\mathrm{L}$ & $44 / \mathrm{F}$ & p.G31791R & Fatigability (26) & Yes (40) & + & + & - & 19 \\
\hline M & $40 / \mathrm{M}$ & p.G31791V & Gait disturbance (24) & Yes (27) & $* *$ & + & + & 19 \\
\hline $\mathrm{N}$ & $46 / M$ & $\begin{array}{l}\text { p.R31783 } \\
\text { V31785del }\end{array}$ & $\begin{array}{l}\text { Foot drop, difficulty in } \\
\text { opening a bottle (41) }\end{array}$ & Yes (41) & + & + & + & 19 \\
\hline $\mathrm{O}$ & $69 / \mathrm{M}$ & p.P31732L & Respiratory failure (67) & Yes (67) & + & - & - & $\begin{array}{l}\text { Present } \\
\text { patient }\end{array}$ \\
\hline
\end{tabular}

NA: not available, ST: Semitendinosus, ACLLs: Anterior compartment of lower legs

*Asymptomatic but found by laboratory tests

** Diffuse muscle involvement

DES and $C R Y A B(4,16,17)$. However, we ruled out mutations in the exons of both of DES and CRYAB by the panel analysis.

HMERF is distributed worldwide, including in Europe, North and South America and Asia $(18,19)$. Several dominant mutations in the TTN A-band have been identified in this disease, including the c.95134T >C, p.C31712R, which is the most frequent HMERF mutation in Europe (18) and Japan (Table 1). Among the mutation patterns, there is still some debate concerning the nature of the p.P31732 L mutation (Table 2). Among 14 individuals who were p.P31732 L heterozygotes or homozygotes, 3 (B-I-1, B-I-2 and D-II-2) showed no signs of muscle disease, two (A-I-1 and A-I-2) showed a mild subclinical phenotype with typical muscle magnetic resonance imaging (MRI) findings, 3 (C-II-1, E-II1 and E-II-2) showed only respiratory failure, 2 (C-II-2 and G-II-1)-including our patient-showed only neck flexor weakness with respiratory failure, 2 (D-II-1 and F-II-1) showed neck flexor and limb weakness as well as respiratory failure, and 2 homozygotes (A-II-1 and B-II-1) had more severe disease with an earlier disease onset (Table 2). Although whether or not selective muscle involvement on imaging was seen in unaffected p.P31732 L carriers (B-I-1, B-I-2, and E-II-2) was not mentioned, it remains possible that the p.P31732 L mutation is a pathogenic variant with variable penetrance.

In contrast, Lange et al. suggested that the p.P31732 L mutation is recessive and can become penetrant when the in cis TTN kinase variant p.R32450W works in synergy on the protein turnover pathways (9). However, the pP31732 L mutation was identified as the cause of HMERF in other families, without any concomitant TTN kinase variant $(5,6,22)$. In addition, Yue et al. reported a 23-year-old Chinese HMERF patient with a heterozygous p.P31732 L mutation without an accompanying kinase domain mutation (23). Furthermore, our patient also had no mutation in the kinase domain of TTN. These findings indicate that the heterozygous p.P31732 L mutation itself is a cause of HMERF, although the phenotype of this mutation is definitely variable.

Muscle weakness in HMERF together with early respiratory failure usually involves the proximal, distal and trunk muscles as the disease progress, and the onset is between 
Table 2. Clinical Features of Individuals Having P.P31732L Mutation.

\begin{tabular}{|c|c|c|c|c|c|c|c|c|}
\hline \multirow[t]{2}{*}{ Patient } & \multirow[t]{2}{*}{$\begin{array}{l}\text { Age/ } \\
\text { sex }\end{array}$} & \multirow[t]{2}{*}{$\begin{array}{c}\text { Initial } \\
\text { manifestation } \\
\text { (age) }\end{array}$} & \multirow[t]{2}{*}{$\begin{array}{c}\text { Muscle } \\
\text { weakness }\end{array}$} & \multirow[t]{2}{*}{$\begin{array}{l}\text { Respiratory } \\
\text { disturbance }\end{array}$} & \multicolumn{2}{|c|}{$\begin{array}{l}\text { Selective muscle } \\
\text { involvement on } \\
\text { imaging }\end{array}$} & \multirow[t]{2}{*}{ Nationality } & \multirow[t]{2}{*}{ References } \\
\hline & & & & & ST & ACLLs & & \\
\hline $\begin{array}{l}\text { A-I-1 } \\
\text { (Father of A-II-1) }\end{array}$ & $59 / \mathrm{M}$ & - & - & - & + & - & Italian & 5 \\
\hline $\begin{array}{l}\text { A-I-2 } \\
\text { (Mother of A-II-1) }\end{array}$ & $56 / \mathrm{F}$ & - & - & - & + & - & Italian & 5 \\
\hline A-II-1(Ho) & $32 / \mathrm{M}$ & $\begin{array}{c}\text { Nocturnal } \\
\text { hypoventilation, } \\
\text { exertional } \\
\text { dyspnea (30) }\end{array}$ & $\begin{array}{l}\text { Neck flexor } \\
\text { Proximal LL } \\
\text { Ankle } \\
\text { dorsiflexion }\end{array}$ & + & $*$ & $*$ & Italian & 5 \\
\hline $\begin{array}{l}\text { B-I-1 } \\
\text { (Father of B-II-1) }\end{array}$ & & & - & - & NA & NA & French** & 5 \\
\hline $\begin{array}{l}\text { B-I-2 } \\
\text { (Mother of B-II-1 }\end{array}$ & & & - & - & NA & NA & French** & 5 \\
\hline B-II-1(Ho) & $36 / \mathrm{M}$ & $\begin{array}{c}\text { Effort } \\
\text { breathlessness } \\
(27)\end{array}$ & $\begin{array}{c}\text { Proximal UL } \\
\text { Proximal LL } \\
\text { Finger extensors } \\
\text { Distal LL }\end{array}$ & & & & & \\
\hline wheelchair bound & + & $*$ & $*$ & French $* *$ & 5 & & & \\
\hline C-II-1 & $56 / \mathrm{M}$ & $\begin{array}{l}\text { Respiratory } \\
\text { failure (42) }\end{array}$ & - & + & NA & - & French** & 5 \\
\hline C-II-2 & $58 / \mathrm{F}$ & $\begin{array}{l}\text { Hypoventilation } \\
\qquad(53)\end{array}$ & Neck flexor & + & NA & NA & French $* *$ & 5 \\
\hline D-II-1 & $57 / \mathrm{M}$ & $\begin{array}{l}\text { Difficulty in } \\
\text { lifting LL (30s) }\end{array}$ & $\begin{array}{l}\text { Neck flexor } \\
\text { Proximal UL } \\
\text { Proximal LL }\end{array}$ & + & NA & NA & British & 6 \\
\hline $\begin{array}{l}\text { D-II-2 } \\
\text { (Younger brother of D-II-1) }\end{array}$ & & - & - & - & NA & NA & British & 6 \\
\hline $\begin{array}{l}\text { E-II-2 } \\
\text { (Sister of E-II-1) }\end{array}$ & & NA & - & + & NA & NA & Portuguese & 22 \\
\hline F-II-1 & $23 / \mathrm{M}$ & $\begin{array}{l}\text { Difficulty in } \\
\text { bending the } \\
\text { neck }(23)\end{array}$ & $\begin{array}{l}\text { Neck flexor } \\
\text { Knee flexor }\end{array}$ & + & + & + & Chinese & 23 \\
\hline G-II-1 & $69 / \mathrm{M}$ & $\begin{array}{l}\text { Respiratory } \\
\text { failure (67) }\end{array}$ & Neck flexor & + & + & - & Japanese & $\begin{array}{l}\text { Preent } \\
\text { patient }\end{array}$ \\
\hline
\end{tabular}

NA, not available. ST, Semitendinosus.Ho, homozygote.

Only A-II-1 and B-II-1 are homozygotes, and others are heterozygous state with p.P31732L.

* Diffuse muscle involvement

** with Portuguese ancestry

the second and the fifth decades of life (2-4). Almost all Japanese patients with HMERF also show an onset before the fifth decade of life and have limb weakness (Table 1). However, the onset of disease in the present patient occurred at 67 years old, which is very late among HMERF individuals, and only weakness of the neck flexor muscles manifested, aside from respiratory muscle involvement. In their first description of HMERF, Edström et al. reported that all patients were characterized by proximal muscle weakness of the upper and lower extremities, with early affection of the neck flexors and respiratory muscles, especially the diaphragm (2). A late-onset HMERF patient like our own might therefore only manifest respiratory failure and mild neck flexor weakness as a clinical presentation. In addition, among seven clinically affected p.P31732 L heterozygotes, five only showed respiratory failure with or without neck flexor weakness (Table 2). Heterozygous patients with this peculiar mutation of TTN might therefore manifest a milder phenotype than those with other dominant mutations with the FN3 domain of the TTN A-band.

In muscle specimens of HMERF, CBs are often located in the subsarcolemmal region, resulting in their being referred to as 'necklace $\mathrm{CBs'}(5,19)$. Uruha et al. reported that necklace $\mathrm{CBs}$ were found in 14 of 17 patients with genetically-confirmed HMERF (19). Based on the result, the sensitivity of the necklace CBs in HMERF was calculated to be $82 \%$. The CBs in our patient did not show a necklacelike alignment, possibly due to the older onset and milder presentation or to the fact that the biopsy was not properly targeted. In either case, these findings suggest that HMERF should be considered in patients associated with both early respiratory failure and non-specific CBs, as in our patient. 
In conclusion, HMERF with a p.P31732 L mutation should be included as a differential diagnosis for ambulatory patients with respiratory insufficiency and neck flexor weakness who harbor non-specific CBs on muscle biopsy specimens.

The authors state that they have no Conflict of Interest (COI).

\section{Acknowledgement}

This study was supported partly by Intramural Research Grant (2-5 and 29-4) for Neurological and Psychiatric Disorders of NCNP; and AMED under Grant Numbers JP20ek0109490h0001 and JP19ek0109285h0003; and JSPS KAKENHI Grant Number $18 \mathrm{~K} 07527$.

\section{Grant Information}

Intramural Research Grant (2-5 and 29-4) for Neurological and Psychiatric Disorders of NCNP; and AMED under Grant Numbers JP20ek0109490h0001 and JP19ek0109285h0003; and JSPS KAKENHI Grant Number 18K07527.

\section{References}

1. Naddaf E, Milone M. Hereditary myopathies with early respiratory insufficiency in adults. Muscle Nerve 56: 881-886, 2017.

2. Edström L, Thornell LE, Albo J, et al. Myopathy with respiratory failure and typical myofibrillar lesions. J Neurol Sci 96: 211-228, 1990.

3. Ohlsson M, Hedberg C, Brådvik B, et al. Hereditary myopathy with early respiratory failure associated with a mutation in A-band titin. Brain 135: 1682-1694, 2012.

4. Tasca G, Udd B. Hereditary myopathy with early respiratory failure (HMERF): Still rare, but common enough. Neuromuscul Disord 28: 268-276, 2018.

5. Palmio J, Evila A, Chapon F, Tasca G, et al. Hereditary myopathy with early respiratory failure: occurrence in various populations. J Neurol Neurosurg Psychiatry 85: 345-353, 2014.

6. Pfeffer G, Barresi R, Wilson IJ, et al. Titin founder mutation is a common cause of myofibrillar myopathy with early respiratory failure. J Neurol Neurosurg Psychiatry 85: 331-338, 2014.

7. Nishikawa A, Mitsuhashi S, Miyata N, Nishino I. Targeted massively parallel sequencing and histological assessment of skeletal muscles for the molecular diagnosis of inherited muscle disorders. J Med Genet 54: 104-110, 2017.

8. Richards S, Aziz N, Bale S, et al. Standards and guidelines for the interpretation of sequence variants: a joint consensus recommendation of the American College of Medical Genetics and Genomics and the Association for Molecular Pathology. Genet Med 17: 405424, 2015.
9. Lange S, Edstrom L, Udd B, Gautel M. Reply: hereditary myopathy with early respiratory failure is caused by mutations in the titin FN3 119 domain. Brain 137: e279, 2014.

10. Gautier G, Verschueren A, Monnier A, Attarian S, Salort-Campana E, Pouget J. ALS with respiratory onset: clinical features and effects of non-invasive ventilation on theprognosis. Amyotroph Lateral Scler 11: 379-382, 2010.

11. Qureshi AI, Choundry MA, Mohammad Y, et al. Respiratory failure as a first presentation of myasthenia gravis. Med Sci Monit 10: CR684-CR689, 2004.

12. Naddaf E, Milone M. Hereditary myopathies with early respiratory insufficiency in adults. Muscle Nerve 56: 881-886, 2017.

13. Walter MC, Reilich $P$, Huebner A, et al. Scapuloperoneal syndrome type kaeser and a wide phenotypic spectrum of adult-onset, dominant myopathies are associated with the desmin mutation $\mathrm{R}$ 350P. Brain 130: 1485-1496, 2007.

14. Selcen D, Engel AG. Myofibrillar myopathy caused by dominant negative alpha B-crystallin mutations. Ann Neurol 54: 804-810, 2003.

15. Selcen D, Muntoni F, Burton BK, et al. Mutation in BAG3 causes severe dominant childhood muscular dystrophy. Ann Neurol 65: 83-89, 2009.

16. Wattjes MP, Kley RA, Fischer D. Neuromuscular imaging in inherited muscle diseases. Eur Radiol 20: 2447-60, 2010.

17. Fischer D, Kley RA, Strach K, et al. Distinct muscle imaging patterns in myofibrillar myopathies. Neurology 71: 758-65, 2008.

18. Palmio J, Leonard-Louis S, Sacconi S, et al. Expanding the importance of HMERF titinopathy: new mutations and clinical aspects. J Neurol 266: 680-690, 2019.

19. Uruha A, Hayashi YK, Oya Y, et al. Necklace cytoplasmic bodies in hereditary myopathy with early respiratory failure. J Neurol Neurosurg Psychiatry 86: 483-489, 2015.

20. Pfeffer G, Chinnery PF. Reply: Hereditary myopathy with early respiratory failure is caused by mutations in the titin FN3 119 domain. Brain 137: e280, 2014.

21. Hedberg C, Melberg A, Dahlbom K, Oldfors A. Hereditary myopathy with early respiratory failure is caused by mutations in the titin FN3 119 domain. Brain 137: e270, 2014.

22. Vasli N, Böhm J, Le Gras S, et al. Next generation sequencing for molecular diagnosis of neuromuscular diseases. Neuropathol 124: 273-283, 2012.

23. Yue D, Gao M, Zhu W, et al. New disease allele and de novo mutation indicate mutational vulnerability of titin exon 343 in hereditary myopathy with early respiratory failure. Neuromuscul Disord 25: 172-176, 2015.

24. Aoki R, Kokubun N, Komagamine T, et al. Selective muscular atrophy in a family with hereditary myopathy with early respiratory failure. Rinsho Shinkeigaku 60: 334-339, 2020 (Article in Japanese).

The Internal Medicine is an Open Access journal distributed under the Creative Commons Attribution-NonCommercial-NoDerivatives 4.0 International License. To view the details of this license, please visit (https://creativecommons.org/licenses/ by-nc-nd/4.0/).

\section{(C) The Japanese Society of Internal Medicine Intern Med Advance Publication}

